\title{
The Effect of Nurses' Death Anxiety on Life Satisfaction During the COVID-19 Pandemic in Turkey
}

\author{
Arzu Karabağ Aydın ${ }^{1}$ (D) Hursit Fidan²
}

Accepted: 17 July 2021 / Published online: 27 July 2021

(c) The Author(s), under exclusive licence to Springer Science+Business Media, LLC, part of Springer Nature 2021

\section{Abstract}

The purpose of the study is to determine the effect of nurses' death anxiety on life satisfaction during the COVID-19 pandemic. This cross-sectional and correlational study was conducted with 411 nurses in Turkey. Data were collected online through Google Forms using a sociodemographic form, the Revised Death Anxiety Scale (RDAS), and the Satisfaction with Life Scale (SWLS). Percentages, means, Pearson's correlation analysis, and hierarchical linear regression models were used to analyze the data. The nurses' mean age was $28.11(\mathrm{SD}=6.27)$ years. More than half of the nurses stated that there were COVID-19 patients in the clinic where they worked (56.0\%) and that they were afraid to provide care to patients diagnosed with COVID-19 (54.5\%). Their mean RDAS total score was $57.33(\mathrm{SD}=16.20)$, indicating moderate death anxiety, and their mean SWLS total score was $2.58(\mathrm{SD}=0.82)$, indicating a low level of life satisfaction. Sociodemographic variables accounted for $8.8 \%$ of the variance. Death anxiety was associated with life satisfaction $(\beta=-0.118, p<0.05)$. Model 3, which included all of the analyzed independent variables, explained $17 \%$ of the variance in life satisfaction $\left(R^{2}=0.171, p<0.001\right)$. This study showed that death anxiety adversely affects life satisfaction. Higher death anxiety among nurses was associated with lower satisfaction with life. Based on the findings, we recommend providing more psychological and communication support to nurses and implementing systematic physical and psychological evaluations of nurses to facilitate early intervention.

Keywords Anxiety $\cdot$ COVID-19 pandemic $\cdot$ Death $\cdot$ Life satisfaction $\cdot$ Nurses

Arzu Karabă Aydın

akarabag.aydin@gmail.com

Hursit Fidan

hursitfidan@sirnak.edu.tr

1 Faculty of Health Sciences Department of Nursing, Kafkas University, 36100 Kars, Turkey

2 Vocational School of Health Services, Medical Services and Techniques, First and Emergency Aid Program, Sirnak University, 73000 Sirnak, Turkey 


\section{Introduction}

In December 2019, an unknown virus linked to a large number of pneumonia cases was detected in Wuhan, Hubei, China (Huang et al., 2020). On February 11, 2020, the International Committee on Taxonomy of Viruses announced that this virus had been named severe acute respiratory syndrome coronavirus 2 (SARS-CoV-2), and on the same date, the disease it caused was officially named coronavirus disease 2019 (COVID-19) by the World Health Organization (WHO, 2020a). The outbreak spread rapidly, affecting human health and economies worldwide (Fan et al., 2020), and on March 11, 2020, the WHO declared COVID19 a pandemic (Cucinotta \& Vanelli, 2020). By May 5, 2021, COVID-19 had infected 153 million people and claimed the lives of nearly 3.2 million people in 222 countries worldwide (WHO, 2021a). In Turkey, 4.9 million confirmed infections and approximately 41,000 deaths were recorded as of May 5, 2021 (WHO, 2021b).

The COVID-19 pandemic has been particularly difficult for healthcare professionals because of its high transmission rate, the many unknowns regarding the virus and disease, and the danger it presents to the lives of health workers (Galehdar et al., 2020). Nurses, who constitute the largest group of health professionals, are on the front lines of the healthcare system during the fight against the pandemic (Fernandez et al., 2020). Nurses who undertake the care and treatment of COVID-19 patients are subject to the highest risk of infection due to their closer and more frequent contact with patients and their longer working hours due to the pandemic (Lai et al., 2020). In addition to their physical health, the mental health of healthcare professionals is another issue to consider during the pandemic (Lázaro-Pérez et al., 2020). Health professionals also witness the suffering and death of COVID-19 patients (Pappa et al., 2020). Nurses have reported that not being able to do anything while patients experienced respiratory distress was difficult for them and had a negative impact on their psyche (Galehdar et al., 2020). Increased exposure to such traumatic events can further increase fear and anxiety among health professionals (Labrague \& De Los Santos, 2020). Anxiety and stress are reported to be more common among healthcare professionals who are directly involved in the recovery process of patients affected by the pandemic compared to the general population (Cheung et al., 2020). The rapid rise in the number of cases not only increases health professionals' workload, but also causes fear that they might infect their family members (Lázaro-Pérez et al., 2020). Anxiety can adversely affect patient safety and lead to the provision of nonstandard care (Apisarnthanarak et al., 2020).

In light of the information presented above, it is expected that one of the most important concerns experienced by nurses during the pandemic is death anxiety. Death anxiety is described as fear and anxiety about death triggered by thoughts of dying (Chen et al., 2020; Cheong et al., 2020). Death anxiety has been implicated in the development of many mental disorders (Menzies et al., 2019). Nurses with death anxiety may exhibit adverse reactions to caring for dying patients (Cheong et al., 2020). Some studies on death anxiety during the COVID-19 
pandemic have shown that nurses have higher death anxiety than other healthcare professionals (Şahin et al., 2020; Tepe Medin et al., 2020). It has been stated that death anxiety is associated with negative health outcomes such as exposure to life-threatening events, a decrease in physical functions, psychological stress, and life dissatisfaction (Rababa et al., 2021).

While nurses worry about getting infected and dying in the clinics where they work during the pandemic, on the other hand, they have to continue their normal lives outside of working hours. Therefore, it is important to obtain satisfaction from life. Nursing is a profession with distinct dimensions that bring joy and satisfaction, but it also involves many difficulties and dilemmas (Bartosiewicz et al., 2020). High life satisfaction is associated with better physical and mental health, and life satisfaction is important in terms of adapting to adversity (Gonzalez-Bernal et al., 2021). In the literature, we found one study on life satisfaction during the COVID-19 pandemic that included nurses in the sample group (Teke et al., 2021). Galehdar et al. (2020) found in their study that nurses experienced various psychological problems while caring for COVID-19 patients.

In our review of the national and international literature, we found no study examining the relationship between death anxiety and life satisfaction in nurses according to variables such as age, gender, education level, and years of experience. In light of the information presented above, we believe that this study will help predict nurses' conditions in the event of extraordinary crisis situations faced by health professionals, such as pandemics. Addressing death anxiety and life satisfaction in the support provided to nurses when coping with crises will enhance nurses' fortitude as they fight on the front lines in these situations. In addition, we believe that this study will enable the identification of nurses with low life satisfaction and thereby provide the opportunity for early interventions to increase their motivation while combating long-term outbreaks.

\section{Methods}

\section{Aim and Research Questions}

This study was conducted to determine the effect of nurses' death anxiety on their life satisfaction during the COVID-19 pandemic. The research questions were as follows: What is the level of death anxiety among nurses during the COVID-19 pandemic? What is the level of life satisfaction among nurses during the COVID-19 pandemic? How does nurses' death anxiety affect their life satisfaction during the COVID-19 pandemic?

\section{Design}

This was a cross-sectional, correlational study. The sample size was calculated with a $95 \%$ confidence interval using a sampling method with a known population. 


$$
\begin{aligned}
& n=\frac{N \cdot t^{2} \cdot p \cdot q}{d^{2(N-1)+t^{2} \cdot p . q}}=\frac{(198,465) \cdot(1.96)^{2} \cdot(0.5)(0.5)}{(0.05)^{2}(198,465-1)+(1.96)^{2}(0.5)(0.5)} \\
& n=383
\end{aligned}
$$

\section{Participants}

The population for the study consisted of nurses working in public and private healthcare institutions/organizations in Turkey. The number of nurses in Turkey was determined as 198,465 as of January 1, 2020 (THS, 2020). The number of nurses needed for the study sample was calculated as 383, and a total of 411 nurses participated in the study.

\section{Data Collection}

The data collection period lasted from June 17, 2020, when the first questionnaire was completed, until the last questionnaire was completed on November 6, 2020. Because social distancing rules precluded conducting face-to-face interviews, the data collection tools for this study were created online using Google Forms. A link was sent to the nurses via email and social media (Facebook, Twitter, Instagram, and WhatsApp). The snowball sampling method was used to recruit the study sample by asking nurses who completed the questionnaire to forward the link to their colleagues. Data collection was continued until the target sample size was reached. All nurses participated voluntarily.

\section{Instruments}

Data were collected using a sociodemographic form, the Revised Death Anxiety Scale (RDAS), and the Satisfaction with Life Scale (SWLS).

\section{Sociodemographic Form}

The sociodemographic form was prepared by the researchers based on the literature (Pehlivan et al., 2020; Piotrkowska et al., 2019; Arslan, 2019) and consisted of 13 questions including sociodemographic characteristics (e.g., age, gender, marital status, and education level) and questions about topics such as working hours, whether the nurses worked in pandemic wards, and their thoughts about death.

RDAS The RDAS was developed by Thorson and Powell (1992) with university students over 18 years of age. Karaca and Y1ld1z (2001) performed a Turkish adaptation and studied its validity and reliability in a normal population. It consists of 25 items rated on a 5 -point Likert scale $(0=$ strongly disagree to $4=$ strongly agree). Seventeen items $(1,2,3,5,6,7,8,9,12,14,15,16,18,19,20,22$, and 24) are positive statements, and eight items $(4,10,11,13,17,21,23$, and 25) are negative statements. Negative items are reverse-scored. The scores range from 0 to 100, with higher scores 
indicating higher death anxiety. The results can be further classified according to the score range into four levels of death anxiety: very low (0-25), mild (25-50), moderate (51-75), and very high (76-100). The Cronbach's alpha value of the RDAS is 0.84 (Karaca \& Y1ldiz, 2001). In this study, the Cronbach's alpha value of the RDAS was calculated as 0.89 .

SWLS The SWLS was developed by Diener et al. (1985) to assess life satisfaction in older adults, and Dağlı and Baysal (2016) performed a Turkish adaptation for use in Turkey. It consists of five items rated on a five-item Likert scale ( $1=$ strongly disagree, $5=$ strongly agree). The total score is the sum of the item scores, and the item mean score is obtained by dividing the total score by five. Low scores indicate low life satisfaction, whereas high scores indicate high life satisfaction. The Cronbach's alpha value of the SWLS is 0.88 (Dağlı \& Baysal, 2016). In this study, the Cronbach's alpha for the SWLS was 0.86 .

\section{Ethical Considerations}

Written permission to use the scales in this study was obtained from the authors. Approval to conduct the study was obtained in advance from the Turkish Ministry of Health. The study adhered to the ethical standards and criteria set forth in the Declaration of Helsinki. Ethics committee approval was obtained from the Kafkas University Faculty of Health Sciences Non-Interventional Research Ethics Committee on May 6, 2020 (approval number: 81829502.903/37). Nurses who voluntarily consented to participate in the study completed the data collection forms.

\section{Data Analysis}

The data were analyzed using SPSS for Windows (version 22.0; IBM Corp, Armonk, NY, USA). Frequency and percentage values were calculated for the categorical variables, and mean and standard deviation values were calculated for the continuous variables. Pearson's correlation analysis was used to characterize the relationships between the variables. A series of hierarchical linear regression analyses were performed to determine which sociodemographic variables and variables related to death and COVID-19 played a role in explaining nursing life satisfaction. In all analyses, the outcome variable was life satisfaction. In Model 1, the explanatory variables were sociodemographic variables (gender, age, marital status, education level, years of professional experience, and clinic in which they currently work). In Model 2, after introducing the sociodemographic variables, we added variables related to death (frequency of thinking about death, frequency of witnessing death in the unit where they work, and losing a first-degree relative) and COVID-19 (whether there were COVID-19 patients in their clinic, whether they were afraid to care for COVID-19 patients, whether they lost a first-degree relative due to COVID-19, and the effect of COVID-19 deaths on their views on the nursing profession). In Model 
3 , death anxiety was added to the third stage. The validity of each of the three models analyzed was evaluated according to $\mathrm{R}^{2}$ and adjusted $\mathrm{R}$, and the statistical significance was assessed using the F test.

\section{Results}

\section{Sociodemographic Characteristics}

The sociodemographic characteristics of the participants are presented in Table 1. The nurses' mean age was 28.11 years $(\mathrm{SD}=6.27)$, and the mean duration of professional experience was 5.96 years $(\mathrm{SD}=5.94)$. Most of the nurses were female $(65.2 \%)$, single $(62.0 \%)$, and held an undergraduate degree (64.4\%). More than half of the nurses stated that there were COVID-19 patients in the clinic where they worked $(56.0 \%)$ and that they were afraid to provide care to patients diagnosed with COVID-19 (54.5\%). In addition, over a third of the nurses reported that deaths caused by the COVID-19 pandemic had negatively affected their views on the nursing profession $(35.8 \%)$, while nearly the same proportion of nurses said their views had not changed $(35.3 \%)$.

\section{Death Anxiety, Life Satisfaction, and Correlation Analysis Results}

The nurses' overall RDAS mean scores and their distribution according to the level of death anxiety are presented in Table 2 . The results showed that $51.3 \%$ of the nurses had moderate anxiety and $31.4 \%$ had mild death anxiety. The mean RDAS total score of the nurses was 57.33 ( $\mathrm{SD}=16.20$; range $=20-1)$, which corresponded to a moderate level of death anxiety. The nurses' mean SWLS scores are shown in Table 3. The mean total SWLS score was $12.91(\mathrm{SD}=4.11$; range $=5-25)$, and the mean item score was $2.58(\mathrm{SD}=0.82$; range $=1-5)$.

The correlations between the variables are presented in Table 4 . There were very weak negative correlations between the level of life satisfaction and age $(r=-0.107$; $p<0.05)$, male gender $(r=-0.153 ; p<0.01)$, frequency of thinking about death $(r=-0.209 ; p<0.01)$, frequency of encountering death in the unit where the nurse worked $(r=-0.105 ; p<0.05)$, and death anxiety $(r=-0.110 ; p<0.05)$. In contrast, the level of life satisfaction tended to be higher among nurses who were not afraid of caring for COVID-19 patients $(r=0.162 ; p<0.01)$ and those who had not lost a first-degree relative to COVID-19 $(r=0.135 ; p<0.01)$.

\section{Hierarchical linear regression analysis results}

In Model 1, gender $(\beta=-0.561 ; p<0.001)$, age $(\beta=-0.114 ; p<0.05)$, education level $(\beta=0.184 ; p<0.001)$, years of work experience $(\beta=0.360 ; p<0.01)$, and the clinic in which they worked $(\beta=0.097 ; p<0.05)$ were found to affect life satisfaction. Sociodemographic variables explained $8.8 \%$ of the variance in life satisfaction $\left(R^{2}=0.088 ; p<0.001\right)$. In Model 2, the added variables of frequency 
Table 1 Sociodemographic characteristics of nurses $(n=411)$

\begin{tabular}{lcc}
\hline Variables & $n$ & $\%$ \\
\hline Gender & & \\
Female & 268 & 65.2 \\
Male & 143 & 34.8 \\
Marital status & & \\
Single & 255 & 62.0 \\
Married & 156 & 38.0 \\
Education level & &
\end{tabular}

$\begin{array}{lll}\text { Health vocational high school } & 66 & 16.1\end{array}$

$\begin{array}{lll}\text { Associates degree } & 80 & 19.5\end{array}$

$\begin{array}{lll}\text { Undergraduate degree } & 265 & 64.4\end{array}$

Current clinic

$\begin{array}{lll}\text { Intensive care } & 87 & 21.2\end{array}$

$\begin{array}{lll}\text { Emergency } & 123 & 29.9\end{array}$

$\begin{array}{lll}\text { Internal medicine } & 67 & 16.3\end{array}$

$\begin{array}{lll}\text { Surgery ward/operating room } & 53 & 12.9\end{array}$

$\begin{array}{lll}\text { Infectious diseases } & 29 & 7.0\end{array}$

$\begin{array}{lll}\text { Family health center } & 18 & 4.4\end{array}$

$\begin{array}{lll}\text { Other } & 34 & 8.3\end{array}$

Frequency of thinking about death

$\begin{array}{lrr}\text { Never } & 33 & 8.0\end{array}$

$\begin{array}{lll}\text { Rarely } & 109 & 26.5\end{array}$

$\begin{array}{lll}\text { Sometimes } & 195 & 47.5\end{array}$

$\begin{array}{lll}\text { Often } & 74 & 18.0\end{array}$

Frequency of encountering death in the clinic

$\begin{array}{lll}\text { Never } & 89 & 21.7\end{array}$

Occasionally $224 \quad 54.5$

$\begin{array}{lll}\text { Often } & 98 & 23.8\end{array}$

Lost a first-degree relative

$\begin{array}{lll}\text { Yes } & 120 & 29.2\end{array}$

$\begin{array}{lll}\text { No } & 291 & 70.8\end{array}$

Presence of COVID-19 patients in the clinic

$\begin{array}{lll}\text { Yes } & 230 & 56.0\end{array}$

$\begin{array}{lll}\text { No } & 181 & 44.0\end{array}$

Afraid to care for COVID-19 patients

$\begin{array}{lll}\text { Yes } & 224 & 54.5\end{array}$

$\begin{array}{lll}\text { No } & 187 & 45.5\end{array}$

Lost a first-degree relative due to COVID-19

$\begin{array}{lll}\text { Yes } & 29 & 7.1\end{array}$

$\begin{array}{lll}\text { No } & 382 & 92.9\end{array}$

The effect of deaths in the COVID-19 pandemic on view of the nursing profession

$\begin{array}{lll}\text { Positive effect } & 53 & 12.9\end{array}$

\begin{tabular}{lll} 
Negative effect & 147 & 35.8 \\
\hline
\end{tabular} 
Table 1 (continued)

\begin{tabular}{lll}
\hline Variables & $n$ & $\%$ \\
\hline No change & 145 & 35.3 \\
I am not sure & 66 & 16.0
\end{tabular}

Mean age (years)

28.11 (SD: 6.27; range: 17-50)

Mean work experience (years)

5.96 (SD: 5.94 years; range: 1-29)

$S D$ standard deviation

Table 2 Mean Revised Death Anxiety Scale (RDAS) scores of the nurses overall and by subgroup $(n=411)$

\begin{tabular}{lll}
\hline & $n(\%)$ & Mean (SD) \\
\hline $\begin{array}{ll}\text { Overall RDAS total score } \\
\text { RDAS subgroups }\end{array}$ & $411(100)$ & $57.33(16.20)$ (moderate) \\
Very low death anxiety (0-25) & $12(2.9)$ & $23.33(1.66)$ \\
Mild death anxiety (26-50) & $129(31.4)$ & $42.33(6.74)$ \\
Moderate death anxiety (51-75) & $211(51.3)$ & $60.81(6.90)$ \\
Very high death anxiety (76-100) & $59(14.4)$ & $84.62(6.37)$
\end{tabular}

$S D$ standard deviation

Table 3 Mean and standard deviation results of nurses in relation to satisfaction with Life Scale (SWLS) $(n=411)$

\begin{tabular}{lc}
\hline SWLS items & Mean (SD) \\
\hline 1. In most ways my life is close to my ideal & $2.67(0.97)$ \\
2. The conditions of my life are excellent & $2.36(0.95)$ \\
3. I am satisfied with my life & $2.82(1.02)$ \\
4. So far, I have gotten the important things I want in life & $2.82(1.04)$ \\
5. If I could live my life over, I would change almost nothing & $2.24(1.09)$ \\
Scale total score & $12.91(4.11)$ \\
Item mean score & $2.58(0.82)$
\end{tabular}

$S D$ standard deviation

of thinking about death $(\beta=-0.148 ; p<0.01)$ and not being afraid of caring for COVID-19 patients $(\beta=0.159 ; p<0.01)$ also affected life satisfaction. Model 2 explained $16 \%$ of the variance in life satisfaction $\left(R^{2}=0.160 ; p<0.001\right)$. In Model 3, the variable of death anxiety was added in addition to the variables in Model 2, and death anxiety $(\beta=-0.118 ; p<0.05)$ was found to affect life satisfaction. Model 3, which included all variables together, explained $17 \%$ of the variance in life satisfaction $\left(R^{2}=0.171 ; p<0.001\right)$. 


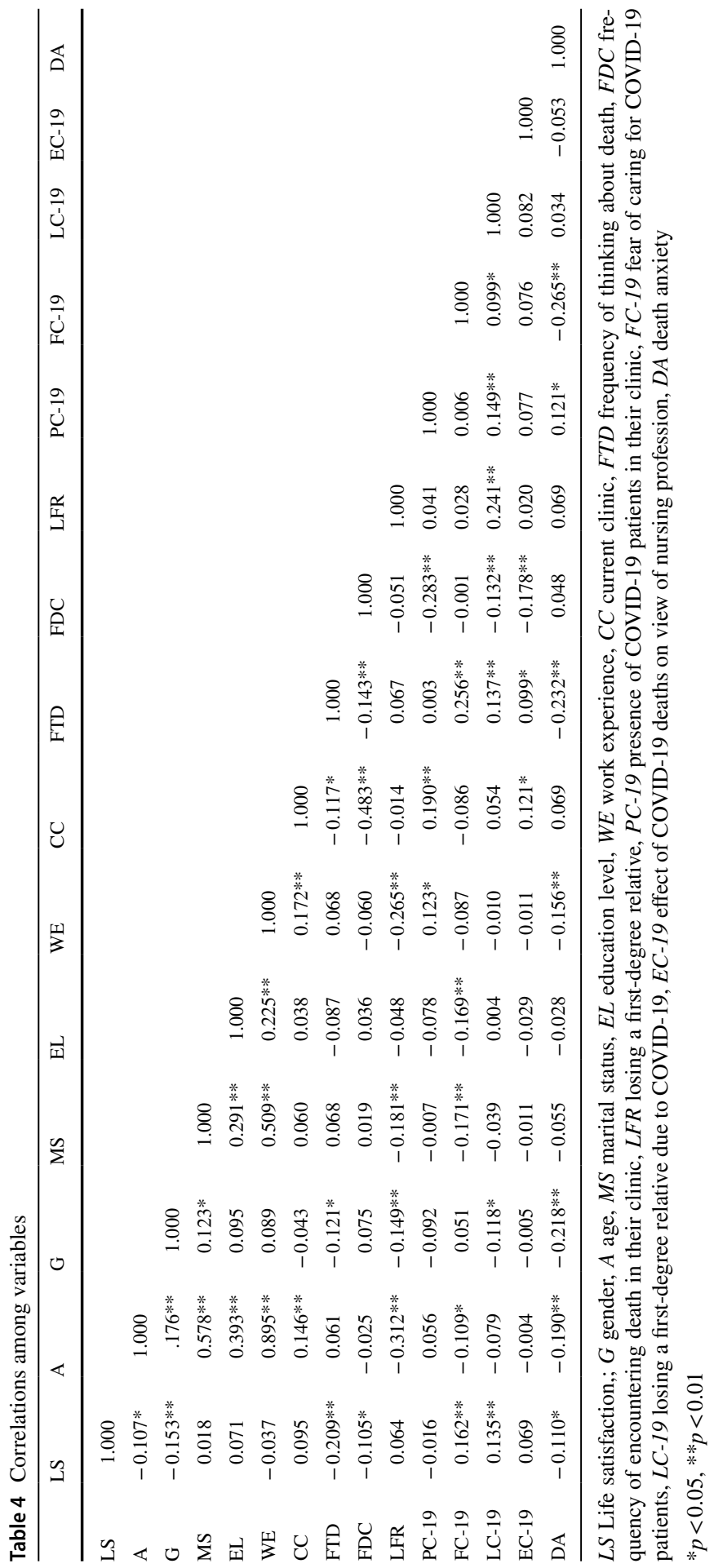




\section{Discussion}

This study was conducted to determine the effect of nurses' death anxiety on their life satisfaction during the COVID-19 pandemic. In this section, the findings obtained from the study are discussed and interpreted in line with the literature.

According to the mean RDAS score in our study, the nurses in our sample had a moderate level of death anxiety during the COVID-19 pandemic (Table 2). However, this was higher than expected because the "moderate" level is the third of four levels in the assessment of death anxiety (scores of 51-75 out of a maximum of 100). Our study using the RDAS to evaluate death anxiety in nurses during the COVID-19 pandemic is the first of its kind. One study used this scale in samples of nurses before the pandemic (Pehlivan et al., 2020). Furthermore, there are similar studies in the literature that used different death anxiety scales in samples of nurses. Galehdar et al. (2020) conducted a qualitative study to discover the psychological distress experienced by nurses during the care of patients with COVID-19 and found that nurses experienced death anxiety due to the high mortality rate of COVID-19, their inability to help patients, and the death of patients who had become infected despite preventive measures. Tepe Medin et al. (2020) determined that nurses had significantly higher death anxiety than physicians. Şahin et al. (2020) also reported that nurses had higher depression, anxiety, and insomnia scores than physicians and other participants. However, a study conducted among patients (Çă̆lar \& Kaçer, 2021) yielded results similar to ours. Çağlar and Kaçer (2021) compared three groups: patients hospitalized due to COVID-19 pneumonia, patients who had a heart attack, and healthy volunteers, and determined that the death anxiety scores of patients hospitalized with COVID-19 pneumonia were significantly higher than those of the other two groups. The fact that the healthy nurses in our study had a level of death anxiety similar to that of patients with COVID-19 pneumonia can be considered an indicator of the degree to which nurses are adversely affected by the pandemic.

The high level of death anxiety among nurses may be attributable to many factors, including being on the front lines of the healthcare system during the pandemic (Fernandez et al., 2020), frequent contact with COVID-19 patients during their long shifts (Lai et al., 2020), witnessing the death of COVID-19 patients (Pappa et al., 2020), and not being able to do anything while patients suffer from respiratory distress (Galehdar et al., 2020). Moreover, nurses' concern about transmitting COVID-19 from the hospital to their families and loved ones is likely a contributing factor. It is believed that lower death anxiety in nurses will enable them to more successfully exhibit positive behavior toward dying patients. In addition, low death anxiety may improve nurses' ability to effectively manage patient care and cope with death.

According to the mean SWLS score obtained in this study, nurses had low life satisfaction during the COVID-19 pandemic (Table 3). Our results were lower than those reported in another study that evaluated life satisfaction among nurses during the COVID-19 pandemic using the SWLS (Teke et al., 2021). In that study, nurses accounted for more than half of the participants and reported 
lower life satisfaction compared to physicians. In the literature, some studies in which data were collected before the pandemic demonstrated higher life satisfaction than that observed in our study (Bartosiewicz et al., 2020; Kim, 2019; Sansó et al., 2020; Uchmanowicz et al., 2019). Bartosiewicz et al. (2020) determined that approximately two-thirds of nurses in Poland had moderate to high life satisfaction. Sansó et al. (2020) reported that life satisfaction was moderate to high in their study of nurses in Spain. In studies conducted in Poland, Uchmanowicz et al. (2019) observed moderate to high life satisfaction in more than three-quarters of nurses and midwives, while Piotrkowska et al. (2019) found that oncology nurses reported an average level of life satisfaction. Compared to our findings, higher levels of life satisfaction during the COVID-19 pandemic were also observed among self-quarantined Chinese people (Li et al., 2021), the general population of Poland (Trzebiński et al., 2020), the general population of Turkey (Özmen et al., 2021), and uninfected adults in China (Zhang et al., 2020b). During the COVID-19 pandemic, healthcare professionals have had to deal with heavy workloads, limited resources, and the risk of exposure to the virus; therefore, it has been stated that healthcare institutions should support their employees to reduce their concerns (Zhang et al., 2020a). Erkal Aksoy and Koçak (2020) reported in their study that more than half of nurses and midwives stated that their lives had worsened since the pandemic and that they had difficulty coping. During the COVID-19 pandemic, it is critical that healthcare professionals are satisfied with their work and lives so that they do not feel the intention to quit (Zhang et al., 2021). In this context, although low life satisfaction may be expected among nurses during extraordinary situations such as a pandemic, it remains a concern that this may have negative effects on patient care.

In our first regression analysis model, we found that nurses' life satisfaction was influenced by their gender, age, level of education, years of experience, and the clinic in which they were working. These sociodemographic variables explained $8.8 \%$ of the variance in life satisfaction (Table 5). When other life satisfaction studies were examined, it was observed that the independent variables examined were limited. Zhang et al. (2021) reported that the life satisfaction of healthcare professionals was positively affected by their average daily exercise time $(b=0.07 ; p=0.04)$ and negatively affected by relocation due to COVID-19 ( $b=-0.51 ; p=0.03)$. Teke et al. (2021) found that life satisfaction was significantly lower among healthcare professionals who cared for COVID19 patients. In a study conducted in the general population, Kumpasoğlu et al. (2021) determined that women had higher life satisfaction than men. Zhang et al. (2020a) reported a positive relationship between life satisfaction and professional $(b=0.22 ; p<0.001)$ and personal $(b=0.15 ; p<0.001)$ support in their study of healthcare professionals. Before the COVID-19 pandemic, Bartosiewicz et al. (2020) reported that nurses with higher education and additional qualifications had higher levels of life satisfaction. In their study of oncology nurses in Poland, Piotrkowska et al. (2019) found that life satisfaction increased with age $(r=0.32 ; p<0.05)$ and years of experience $(r=0.33 ; p<0.05)$. Our second model showed that the frequency of thinking about death and the fear of caring for COVID-19 patients also affected life satisfaction, explaining $16 \%$ of 


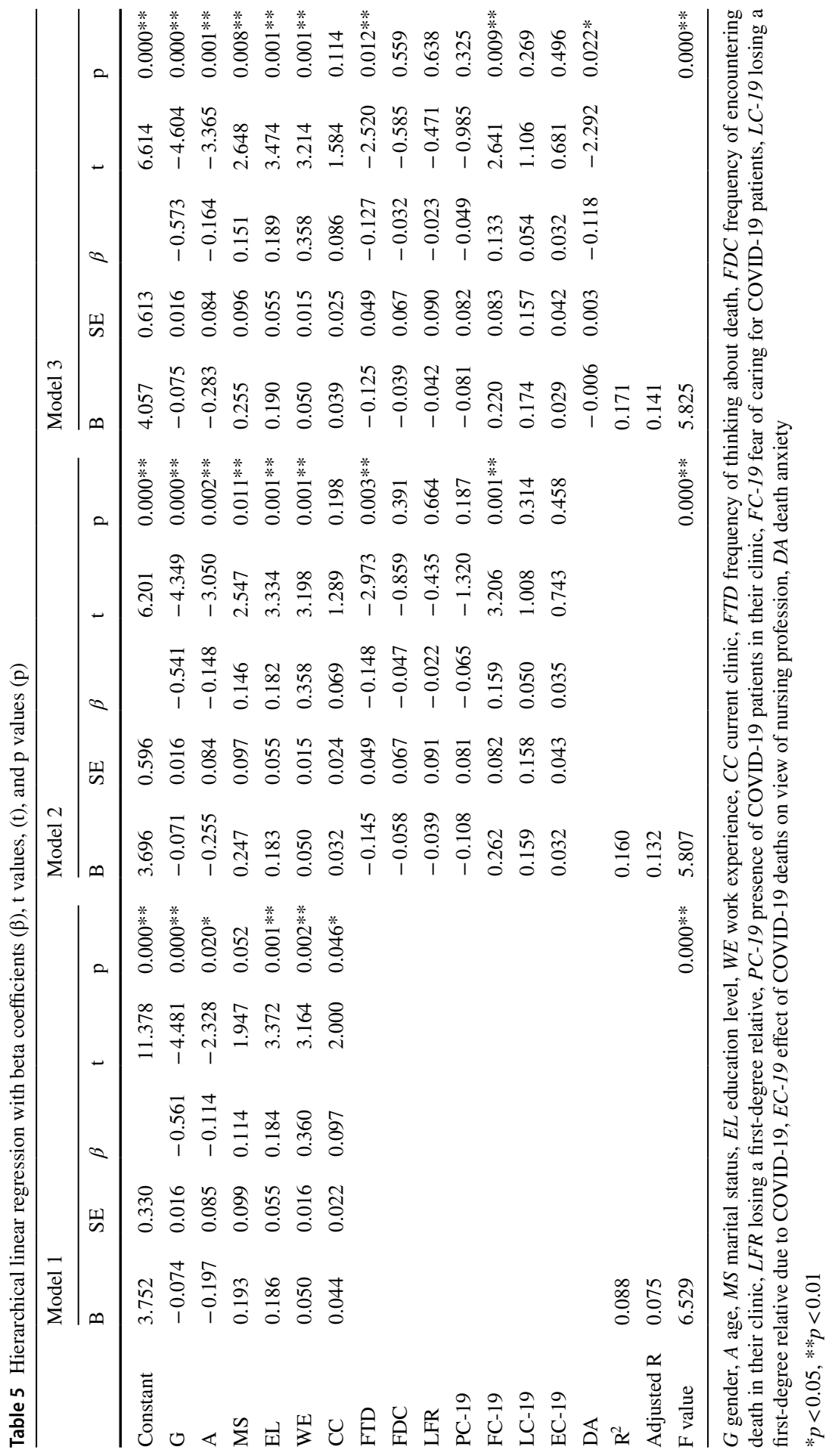


the variance in life satisfaction (Table 5). Özmen et al. (2021) reported that life satisfaction was lower among participants who feared COVID-19 $(\beta=-0.115$, $t=-6.448 ; p<0.001$ ), while Bozdağ and Ergün (2020) reported in their study on nurses and physicians that those who were worried about being infected with COVID-19 had lower psychological resilience $(\beta=-0.20 ; p<0.01)$.

The third model, which added death anxiety to the other variables, indicated that death anxiety affects life satisfaction, and the model explained $17 \%$ of the variance in life satisfaction (Table 5). To our knowledge, no previous study has demonstrated the impact of death anxiety on life satisfaction among nurses. However, Trzebiński et al. (2020) detected a negative association between anxiety and life satisfaction in a normal population $(\beta=-0.254 ; p<0.001)$. In a study of university students conducted by Arslan (2019), students with low death anxiety had higher life satisfaction. In contrast, Kumpasoğlu et al. (2021) did not detect a significant relationship between life satisfaction and death anxiety in their study of the general population. Considering the general sense of life satisfaction among nurses, satisfaction with their work is related to a readiness to learn and take on new challenges (Bartosiewicz et al., 2020). The WHO confirmed on December 31, 2020, that mutation-related changes have been reported in SARS-CoV-2 and stated that this was a concerning development (WHO, 2020b). Therefore, as it is uncertain how long this pandemic will continue and there is always the possibility of new pandemics, studies to characterize the situation faced by nurses, a key group in the healthcare system, play an important role in protecting their well-being and enhancing their occupational performance. The results of these studies will reveal what kind of support nurses need and enable the planning of interventional studies focusing on these areas. In addition, this study can also be regarded as an opportunity to provide support to nurses after the pandemic ends.

\section{Conclusion and recommendations}

The results showed that $51.3 \%$ of the nurses had moderate death anxiety and $31.4 \%$ had mild death anxiety. The mean RDAS total score of the nurses was $57.33(\mathrm{SD}=16.20)$. The mean total SWLS score was $12.91(\mathrm{SD}=4.11)$, and the mean item score was $2.58(\mathrm{SD}=0.82)$. In Model 1 , sociodemographic variables explained $8.8 \%$ of the variance in life satisfaction. Model 2 explained $16 \%$ of the variance in life satisfaction. Model 3, which included all variables together, explained $17 \%$ of the variance in life satisfaction. This study showed that death anxiety adversely affects life satisfaction. As nurses' death anxiety increased, their satisfaction with life decreased. Based on our findings, we recommend providing more psychological and communication support to high-risk groups such as nurses, the largest health professional group, implementing systematic physical and psychological evaluation of nurses to facilitate early intervention, and organizing structured training to improve nurses' knowledge and coping methods in relation to death. 


\section{Study Limitations}

The limitations of this study are that the data were collected online, and it is not possible to determine whether the sample represents Turkey in terms of its seven geographical regions.

Acknowledgements The authors would like to thank the nurses who volunteered to participate in the study.

\section{References}

Apisarnthanarak, A., Apisarnthanarak, P., Siripraparat, C., Saengaram, P., Leeprechanon, N., \& Weber, D. (2020). Impact of anxiety and fear for COVID-19 toward infection control practices among Thai healthcare workers. Infection Control and Hospital Epidemiology, 41(9), 1093-1094. https://doi. org/10.1017/ice.2020.280

Arslan, A. (2019). Examination of the relationship between life satisfaction and death anxiety among university students. Journal of Research in Education and Society, 6(1), 113-129

Bartosiewicz, A., Łuszczki, E., \& Dereń, K. (2020). Personalized nursing: How life satisfaction and occupational burnout influence new competences of polish nurses. Journal of Personalized Medicine, 10(2), 48. https://doi.org/10.3390/jpm10020048

Bozdağ, F., \& Ergün, N. (2020). Psychological resilience of healthcare professionals during covid-19 pandemic. Psychological Reports. https://doi.org/10.1177/0033294120965477

Çağlar, A., \& Kaçer, İ. (2021). Anxiety levels in patients admitted to the emergency department with myocardial infarction or COVID-19 pneumonia. Psychology, Health and Medicine. https://doi.org/ 10.1080/13548506.2021.1876893

Chen, X., Liu, T., Li, P., Wei, W., \& Chao, M. (2020). The relationship between media involvement and death anxiety of self-quarantined people in the COVID-19 outbreak in China: The mediating roles of empathy and sympathy. Omega Journal of Death and Dying. https://doi.org/10.1177/0030222820 960283

Cheong, C., Ha, N., Tan, L., \& Low, J. (2020). Attitudes towards the dying and death anxiety in acute care nurses - can a workshop make any difference? A mixed-methods evaluation. Palliative and Supportive Care, 18(2), 164-169. https://doi.org/10.1017/S1478951519000531

Cheung, T., Fong, T. K. H., \& Bressington, D. (2020). COVID-19 under the SARS cloud: Mental health nursing during the pandemic in Hong Kong. Journal of Psychiatric and Mental Health Nursing, 28(2), 115-117. https://doi.org/10.1111/jpm.12639

Cucinotta, D., \& Vanelli, M. (2020). WHO declares COVID-19 a pandemic. Acta Bio Medica, 91(1), 157. https://doi.org/10.23750/abm.v91i1.9397

Dağlı, A., \& Baysal, N. (2016). Adaptation of the satisfaction with life scale into Turkish: The study of validity and reliability. Electronic Journal of Social Sciences, 15(59), 1250-1262. https://doi.org/10. 17755/esosder.75955

Diener, E. D., Emmons, R. A., Larsen, R. J., \& Griffin, S. (1985). The satisfaction with life scale. Journal of Personality Assessment, 49(1), 71-75. https://doi.org/10.1207/s15327752jpa4901_13

Erkal Aksoy, Y., \& Koçak, V. (2020). Psychological effects of nurses and midwives due to COVID-19 outbreak: The case of Turkey. Archives of Psychiatric Nursing, 34(5), 427-433. https://doi.org/10. 1016/j.apnu.2020.07.011

Fan, Y., Wang, X., Jun Zhang, J., Mo, D., \& Xiao, X. (2020). The risk factors for the exacerbation of COVID-19 disease: A case-control study. Journal of Clinical Nursing, 30, 725-731. https://doi.org/ 10.1111/jocn.15601

Fernandez, R., Lord, H., Halcomb, E., Moxham, L., Middleton, R., Alananzeh, I., \& Ellwood, L. (2020). Implications for COVID-19: A systematic review of nurses' experiences of working in acute care hospital settings during a respiratory pandemic. International Journal of Nursing Studies, 111, 103637. https://doi.org/10.1016/j.ijnurstu.2020.103637 
Galehdar, N., Toulabi, T., Kamran, A., \& Heydari, H. (2020). Exploring nurses' perception of taking care of patients with coronavirus disease (COVID-19): A qualitative study. Nursing Open, 8(1), 171179. https://doi.org/10.1002/nop2.616

Gonzalez-Bernal, J. J., Rodríguez-Fernández, P., Santamaría-Peláez, M., González-Santos, J., León-delBarco, B., Minguez, L. A., \& Soto-Cámara, R. (2021). Life satisfaction during forced social distancing and home confinement derived from the COVID-19 pandemic in Spain. International Journal of Environmental Research and Public Health, 18(4), 1474. https://doi.org/10.3390/ijerph18041474

Huang, C., Wang, Y., Li, X., Ren, L., Zhao, J., Hu, Y., Zhang, L., Fan, G., Xu, J., Gu, X., Cheng, Z., Yu, T., Xia, J., Wei, Y., Wu, W., Xie, X., Yin, W., Li, H., Liu, M., .. Cao, B. (2020). Clinical features of patients infected with 2019 novel coronavirus in Wuhan, China. The Lancet, 395(10223), 497-506. https://doi.org/10.1016/S0140-6736(20)30183-5

Karaca, F., \& Y1ldı, M. (2001). The validity and reliability study of Turkish version of Thorson-Powell Death Anxiety scale in a normal population. Tabula Rasa, 1(1), 43-55.

Kim, J. (2019). Nursing students' relationships among resilience, life satisfaction, psychological wellbeing, and attitude to death. Korean Journal of Medical Education, 31(3), 251-260. https://doi.org/ 10.3946/kjme.2019.135

Kumpasoğlu, G. B., Eltan, S., Merdan-Yıldız, E. D., \& Batıgün, A. D. (2021). Mediating role of life satisfaction and death anxiety in the relationship between dark triad and social media addiction. Personality and Individual Differences, 172, 110606. https://doi.org/10.1016/j.paid.2020.110606

Labrague, L. J., \& De Los Santos, J. (2020). COVID-19 anxiety among front-line nurses: Predictive role of organisational support, personal resilience and social support. Journal of Nursing Management, 28(7), 1653-1661. https://doi.org/10.1111/jonm.13121

Lai, J., Ma, S., Wang, Y., Cai, Z., Hu, J., Wei, N., Wu, J., Du, H., Chen, T., Li, R., Tan, H., Kang, L., Yao, L., Huang, M., Wang, H., Wang, G., Liu, Z., \& Hu, S. (2020). Factors associated with mental health outcomes among health care workers exposed to coronavirus disease 2019. JAMA Network Open, 3(3), e203976. https://doi.org/10.1001/jamanetworkopen.2020.3976

Lázaro-Pérez, C., Martínez-López, J. Á., Gómez-Galán, J., \& López-Meneses, E. (2020). Anxiety about the risk of death of their patients in health professionals in Spain: Analysis at the peak of the COVID-19 pandemic. International Journal of Environmental Research and Public Health, 17(16), 5938. https://doi.org/10.3390/ijerph17165938

Li, A., Wang, S., Cai, M., Sun, R., \& Liu, X. (2021). Self-compassion and life-satisfaction among Chinese self-quarantined residents during COVID-19 pandemic: A moderated mediation model of positive coping and gender. Personality and Individual Differences, 170, 110457. https://doi.org/10. 1016/j.paid.2020.110457

Menzies, R. E., Sharpe, L., \& Dar-Nimrod, I. (2019). The relationship between death anxiety and severity of mental illnesses. The British Journal of Clinical Psychology, 58(4), 452-467. https://doi.org/10. 1111/bjc. 12229

Özmen, S., Özkan, O., Özer, Ö., \& Yanardağ, M. Z. (2021). Investigation of COVID-19 fear, well-being and life satisfaction in Turkish society. Social Work in Public Health, 36(2), 164-177. https://doi. org/10.1080/19371918.2021.1877589

Pappa, S., Ntella, V., Giannakas, T., Giannakoulis, V. G., Papoutsi, E., \& Katsaounou, P. (2020). Prevalence of depression, anxiety, and insomnia among healthcare workers during the COVID-19 pandemic: A systematic review and meta-analysis. Brain, Behavior, and Immunity, 88, 901-907. https:// doi.org/10.1016/j.bbi.2020.05.026

Pehlivan, S., Lafçı, D., Vatansever, N., \& Yıldız, E. (2020). Relationship between death anxiety of Turkish nurses and their attitudes toward the dying patients. Omega- Journal of Death and Dying, 82(1), 128-140. https://doi.org/10.1177/0030222819895122

Piotrkowska, R., Jarzynkowski, P., Książek, J., \& Mędrzycka-Dąbrowska, W. (2019). Satisfaction with life of oncology nurses in Poland. International Nursing Review, 66(3), 374-380. https://doi.org/10. 1111/inr. 12521

Rababa, M., Hayajneh, A. A., \& Bani-Iss, W. (2021). Association of death anxiety with spiritual wellbeing and religious coping in older adults during the COVID-19 pandemic. Journal of Religion and Health, 60, 50-63. https://doi.org/10.1007/s10943-020-01129-x

Şahin, M. K., Aker, S., Şahin, G., \& Karabekiroğlu, A. (2020). Prevalence of depression, anxiety, distress and insomnia and related factors in healthcare workers during COVID-19 pandemic in Turkey. Journal of Community Health, 45(6), 1168-1177. https://doi.org/10.1007/s10900-020-00921-w

Sansó, N., Galiana, L., Oliver, A., Tomás-Salvá, M., \& Vidal-Blanco, G. (2020). Predicting professional quality of life and life satisfaction in Spanish nurses: A cross-sectional study. International Journal 
of Environmental Research and Public Health, 17(12), 4366. https://doi.org/10.3390/ijerph1712 4366

Teke, N., Özer, Z., \& Bahçecioğlu Turan, G. (2021). Analysis of health care personnel's attitudes toward complementary and alternative medicine and life satisfaction due to COVID-19 pandemic. Holistic Nursing Practice, 35(2), 98-107. https://doi.org/10.1097/HNP.0000000000000431

Tepe Medin, Ş, Hintistan, S., \& Özoran, Y. (2020). Dahili Kliniklerde Çalışan Hekim ve Hemşirelerde Ölüm Kaygısının Belirlenmesi. Journal of Hacettepe University Faculty of Nursing, 7(3), 262-270. https://doi.org/10.31125/hunhemsire.834176

Thorson, J. A., \& Powell, F. C. (1992). A revised death anxiety scale. Death Studies, 16(6), 507-521. https://doi.org/10.1080/07481189208252595

Trzebiński, J., Cabański, M., \& Czarnecka, J. Z. (2020). Reaction to the COVID-19 pandemic: The influence of meaning in life, life satisfaction, and assumptions on world orderliness and positivity. Journal of Loss and Trauma, 25(6-7), 544-557. https://doi.org/10.1080/15325024.2020.1765098

Turkey's Health Statistics. (2020). The most up-to-date data on health statistics in the reply of minister Koca. https://www.dogrulukpayi.com/bulten/turkiye-nin-saglik-istatistikleri\#: :text=Bakan\%20Koc a'n\%C4\%B1n\%20a\%C3\%A7\%C4\%B1klad\%C4\%B1\%C4\%9F\%C4\%B1\%20\%C3\%BCzere,2'si\% 20\%C3\%B6zel\%20sekt\%C3\%B6rde\%20\%C3\%A7al\%C4\%B1\%C5\%9F\%C4\%B1

Uchmanowicz, I., Manulik, S., Lomper, K., Rozensztrauch, A., Zborowska, A., Kolasińska, J., \& Rosińczuk, J. (2019). Life satisfaction, job satisfaction, life orientation and occupational burnout among nurses and midwives in medical institutions in Poland: A cross-sectional study. British Medical Journal Open, 9(1), e024296. https://doi.org/10.1136/bmjopen-2018-024296

World Health Organization. (2020a). Naming the coronavirus disease (COVID-19) and the virus that causes it. https://www.who.int/emergencies/diseases/novel-coronavirus-2019/technical-guidance/ naming-the-coronavirus-disease-(COVID-2019)-and-the-virus-that-causes-it

World Health Organization. (2020b). Disease Outbreak News. https://www.who.int/csr/don/31-december2020-sars-cov2-variants/en/ https://www.who.int/csr/don/31-december-2020-sars-cov2-variants/en/

World Health Organization. (2021a). WHO Coronavirus (COVID-19) dashboard. https://covid19.who. int/ https://covid19.who.int/

World Health Organization. (2021b). Turkey situation. https://covid19.who.int/region/euro/country/tr https://covid19.who.int/region/euro/country/tr

Zhang, S. X., Sun, S., Afshar Jahanshahi, A., Alvarez-Risco, A., Ibarra, V. G., Li, J., \& Patty-Tito, R. M. (2020a). Developing and testing a measure of COVID-19 organizational support of healthcare workers-Results from Peru, Ecuador, and Bolivia. Psychiatry Research, 291, 113174. https://doi.org/10. 1016/j.psychres.2020.113174

Zhang, S. X., Wang, Y., Rauch, A., \& Wei, F. (2020b). Unprecedented disruption of lives and work: Health, distress and life satisfaction of working adults in China one month into the COVID-19 outbreak. Psychiatry Research, 288, 112958. https://doi.org/10.1016/j.psychres.2020.112958

Zhang, S. X., Chen, J., Afshar Jahanshahi, A., Alvarez-Risco, A., Dai, H., Li, J., \& Patty-Tito, R. M. (2021). Succumbing to the COVID-19 pandemic-healthcare workers not satisfied and intend to leave their jobs. International Journal of Mental Health and Addiction. https://doi.org/10.1007/ s11469-020-00418-6

Publisher's Note Springer Nature remains neutral with regard to jurisdictional claims in published maps and institutional affiliations. 